\title{
Association of paraoxonase polymorphisms with carotid artery atherosclerosis in essential hypertension patients
}

L. Han ${ }^{1,2}$, X.J. Xu ${ }^{1,2}$, X.H. Liang ${ }^{1,2}$ and J. Ma ${ }^{1,2}$

${ }^{1}$ State Key Laboratory Incubation Base of Xinjiang Major Diseases Research, First Affiliated Hospital of Xinjiang Medical University, Urumqi, Xinjiang, China ${ }^{2}$ Department of Hypertension, The First Affiliated Hospital of Xinjiang Medical University, Urumqi, Xinjiang, China

Corresponding author: X.J. Xu

E-mail: zcxu2002@medmail.com.cn

Genet. Mol. Res. 12 (4): 5174-5185 (2013)

Received March 28, 2013

Accepted July 3, 2013

Published October 30, 2013

DOI http://dx.doi.org/10.4238/2013.October.30.2

\begin{abstract}
We investigated the relationships between paraoxonase genetic polymorphisms and essential hypertension in carotid artery atherosclerotic patients. The study included 353 Han participants and 240 Uighur participants from Xinjiang; they were further divided into two groups: essential hypertension with carotid artery atherosclerosis (CAAD group) and essential hypertension without carotid artery atherosclerosis (control group). Genotypes were detected by PCR, followed by restriction analyses with specific endonucleases. In Han people, the $\mathrm{M}$ allele frequency was significantly higher in the CAAD group than in the control group. The $\mathrm{CC} / \mathrm{CS}$ genotype and $\mathrm{C}$ allele frequencies were significantly higher in the CAAD group than in the control group. Logistic regression analysis demonstrated that PON1 $55 \mathrm{M}$ allele [odds ratio $(\mathrm{OR})=1.889$ ] and $\mathrm{PON} 2311 \mathrm{C}$ allele $(\mathrm{OR}=1.692)$ are independent risk factors for CAAD. Combined genotype analysis showed that PON1 55M and PON2 311C alleles are independent risk
\end{abstract}


factors for CAAD $(\mathrm{OR}=1.428)$. In the Uighur population, the $\mathrm{CC} /$ $\mathrm{CS}$ genotype and $\mathrm{C}$ allele frequencies were significantly higher in the CAAD group than in the control group. Logistic regression analysis demonstrated that the PON2 $311 \mathrm{C}$ allele is an independent risk factor for CAAD. We conclude that the PON1 55M and PON2 311C alleles are independent risk factors for CAAD in essential hypertension patients from the Xinjiang Han population. We also conclude that the PON2 $311 \mathrm{C}$ allele is a risk factor for CAAD in essential hypertension patients from the Xinjiang Uighur population.

Key words: Paraoxonase (PON); Gene polymorphism; Essential hypertension; Carotid artery atherosclerotic disease

\section{INTRODUCTION}

Ischemic stroke is one of the dangerous diseases threatening people's health and lives. Carotid artery atherosclerotic disease (CAAD) reflects systemic atherosclerosis as a window, the research of internal and abroad has confirmed CAAD acts as a predictor of cardiovascular disease for cerebral infarction and coronary heart disease (Yen et al., 2008; Jin and Wang, 2010). Carotid artery stenosis causes stroke, accounting for $15 \%$ of ischemic stroke, and $>70 \%$ of the carotid artery stenosis patients with stroke incidence is as high as $13 \%$, with $1-2 \%$ for symptomless patients. It is related to atheromatous plaque on stability in narrow places (Jander et al., 2001). CAAD is believed to be the primary cause of ischemic stroke (Nagai et al., 2001). Therefore, the basic study of CAAD is especially important for people's health. The mechanisms of CAAD are multiple. Carotid atherosclerosis is a complex chronic inflammation lesion involving many factors, such as high blood pressure, diabetes, smoking, low-density lipoprotein cholesterol, triglycerides and high-density lipoprotein cholesterol, obesity, age, gender, family history with coronary heart disease and diabetes, social economic factors, and they are all atherosclerosis risk factors, which can accelerate the occurrence and development of atherosclerosis. A recent study found that CAAD was related to some genetic polymorphisms including those of fatty liver enzymes, apolipoprotein, cholesterol fat transfer protein, phosphorus oxygen lyase, angiotensin 1-converting enzyme, matrix metalloproteinases 3 , inflammatory cell factor, and endothelial nitric oxide synthase (Zhao and Ding, 2005). In addition to other risk factors, it is still concerned with individual genetic susceptibility. Recent research indicates that atherosclerosis is a multiple gene disease and that it is the result of environmental and genetic factors working together (Jander et al., 2001). Some genetic alleosis can make carotid's endomembrace and tunica media film thickness (IMT) changing, leading atherosclerosis occurrence and development, It could eventually lead to ischemic cerebrovascular event. Genetics probably plays an important role in the development of carotid artery atherosclerotic disease (Zhao and Ding, 2005). The relationship between the paraoxonase (PON) gene family and carotid artery atherosclerotic disease has been a hotspot in recent years.

The PON gene family consists of three members, PON1, PON2, and PON3, located adjacent to each other on the long arm of chromosome 7q21.3-q22.1 in humans (Primo-Parmo et al., 1996). PON1 has been demonstrated to protect LDL against oxidation, to reverse the biological effects of oxidized LDL, and to preserve the function of HDL by inhibiting its 
oxidation (Mackness et al., 1993; Watson et al., 1995; Aviram et al., 1998; Durrington et al., 2001). PON2 has been reported to possess antioxidant properties and to be able to retard the oxidation of preformed mildly oxidized LDL ( $\mathrm{Ng}$ et al., 2001). One function of PON2 may be to act as a cellular antioxidant, protecting cells from oxidative stress ( $\mathrm{Ng}$ et al., 2005). PON expression and activity is under strong genetic influence (Roest et al., 2006).

At present, research about the relationship between PON 1 Q192R gene polymorphism and carotid atherosclerotic lesions is more than PON1L55M, the results is also controversial. Rontu et al. (2003) confirmed that PON1 SSM alleles carriers occuring artery atherosclerosis lesion is more than homozygous LL, MM genotype is more than LL genotype increased significantly. However, there are opposing views. Malin et al. (2001a) and Harangi et al. (2008) considered that homozygous LL was clearly relevant to the occurrence and severity of carotid artery atherosclerosis, $55 \mathrm{~L}$ alleles is the independent risk factors of carotid atherosclerosis; Mackness et al. (2001) study on 1000 German coronary artery disease (CAD) patients and Hong et al. (2001) study on 191 Korea CAD patients did not draw a conclusions that PON1 L55M polymorphisms was related with AS. Various research results are not in agreement, possibly because of the diversity in design of experiments, ethnic differences of allele frequencies, interaction between the gene and environment and the imbalance of the genetic polymorphism chain.

PON2 has two genetic polymorphisms, respectively PON2 2 A149G (Ala Gly) and PON2 2 C311S (Cys Ser) (Mochizuki et al., 1998). There are different reports about PON2 causing atherosclerosis. Sanghera et al. (1998) found that PON2 S311 allele frequency of $\mathrm{CAD}$ patients was significantly higher than that of normal controls $(0.71$ and $0.16, \mathrm{P}=0.016)$ in India. Imai et al. (2000) considered that PON2 C311S genetic polymorphism was unrelated to coronary heart disease and ischemic stroke in Japan. PON2 C311S genotype and gene frequency distribution are related to race and geographical environment, as shown by the study of the 3 PON2 C311S genotypes and their distribution in various populations: Han in GuangDong, SS 72.6\%, CS 25.6\%, and CC 1.7\% (Wang et al., 2004); Han in Tianjin, SS 72.18\%, CS $25.02 \%$, and CC 2.82\% (Zou and Ge, 1999); Japanese, SS 65\%, CS 30\%, CC 5\% (Imai et al., 2000); and Indians, SS 40.2\%, CS 42.3\%, CC 17.5\% (Sanghera et al., 1998).

Carotid atherosclerotic lesions is related with multiple genes and much environment factor, many susceptibility genes have been found likely, but the repeat and demonstration research in different crowd is rarely. At present, the reports about PON1 L55M genes and PON2 2 C311S gene indicate some dispute, which may be due to ethnic differences, sample quantity and environmental factors, especially where the frequency distribution for these gene types are relevant to race and population. Xinjiang consists of many national settlements, including Han, Uighur, Kazak and so on, and it is in a special geographical environment, Hypertension patients is in the majority, The study of the correlation between carotid artery atherosclerotic disease in Han and Uighur essential hypertension patients with genetic polymorphism of PON1 L55M and PON2 2 C311S genes, may determine whether these genes are independent risk factors for carotid atherosclerotic lesions. It will provide more effective individual prevention and treatment strategies for Han and Uighur essential hypertension patients, and offer some reliable basis for studying human genetic susceptibility genes.

The purpose of the present study was to assess the relationship between PON1-55 and PON2-311 polymorphisms and carotid artery atherosclerotic disease in the Xinjiang Han and Uighur population with essential hypertension. 


\section{MATERIAL AND METHODS}

\section{Subjects}

The study population consisted of 353 individuals of the Han population with essential hypertension and 240 of the Uighur population with essential hypertension, aged between 40 and 70 years. All subjects were recruited from the Heart Center of the First Affiliated Hospital of Xinjiang Medical University between January 2006 and January 2009. This study was conducted in accordance with the Declaration of Helsinki. This study was conducted with approval from the Ethics Committee of the First Affiliated Hospital of Xinjiang Medical University. Written informed consent was obtained from all participants. All subjects had a primary medical treatment and no drug intake. They were separately divided into two groups: essential hypertension with CAAD (CAAD group) and essential hypertension without CAAD (control group). There was no significant difference in age and gender between the two group. Subjects with secondary hypertension, diabetes, liver and kidney function abnormality, infection, autoimmune diseases, cancer, hyperthyroidism, hypothyroidism, peripheral vascular disease, or congenital vascular malformation were excluded.

All subjects underwent a structured clinical interview, a physical examination, blood pressure measurement, three ultrasound examinations and a complete blood chemistry panel including fasting plasma glucose (FPG), glycated serum proteins ( $\mathrm{HbA} 1 \mathrm{C})$, triglycerides (TG), total cholesterol (TC), high-density lipoprotein cholesterol (HDL-C), low-density lipoprotein cholesterol (LDL-C), apolipoprotein A1 (ApoA1) and apolipoprotein B (ApoB). Blood pressure measurement: according to China hypertension guidelines (2005) for diagnostic criteria. Baumanometer must be calibrated. The individuals had measurements taken at rest after at least $5 \mathrm{~min}$, measuring the right brachial blood pressure in the sitting position, with the elbow situated at the same level as the heart; the stethoscope was placed on the brachial artery, with one time Korotkoff sound (first clear voice) for systolic blood pressure and the fifth sound (voice suddenly disappears) for diastolic blood pressure, where blood pressure readings were according to the mercury meniscus. Measurements were repeated three times until the difference of two blood pressure readings was less than $5 \mathrm{mmHg}$, where the average number of three time measurements was taken for systolic blood pressure and diastolic blood pressure. All participants were overnight fasting more than $12 \mathrm{~h}$, Peripheral venous blood (4-5 mL) was drawn from fasting participants, and the samples were all analyzed with an automatic biochemistry instrument at the inspection center, the First Affiliated Hospital of Xinjiang Medical University.

\section{Genotype analysis}

In addition, 3-4 $\mathrm{mL}$ of drawn peripheral venous blood were immediately placed in 10$\mathrm{mL}$ tubes containing EDTA, which were then completely mixed, and stored at $-80^{\circ} \mathrm{C}$. Genomic DNA was extracted by standard methods including phenol/chloroform/isoamyl alcohol.

\section{Carotid ultrasonography}

Color-coded equipment (PHILIPS IE5500) with a 10-MHz transducer was used to 
determine atherosclerotic vessel wall abnormalities of the carotid arteries. The examinations were done by a single and experienced physician. CAAD was defined as intima-media thickness (IMT) $\geq 1.0 \mathrm{~mm}$ or the formation of the atherosclerotic plaque (Mathiesen et al., 2001).

\section{Isolation of DNA and genotype analysis}

DNA was prepared from white blood cells by phenol extraction. PON1 has more than two common polymorphisms sites, leucine (L)/methionine (M) at position 55 and glutamic acid (Q)/arginine (R) at position 192. In the 55 site polymorphism, the enzyme appears as the $\mathrm{M}$ type (methionine) or L type (leucine), where the changes may influence levels of PON1 in serum. PON2 has two common polymorphisms sites, alanine $(\mathrm{A}) /$ glycine $(\mathrm{G})$ at position 148 and cysteine $(\mathrm{C}) /$ serine $(\mathrm{S})$ at position 311 , where the PON genotype coding polymorphisms may be related to cardiovascular disease.

\section{PCR}

DNA was extracted from white blood cells using saturated phenol/chloroform, and dissolved in TE solution until use.

Genotyping of the PON1 L55M polymorphism was done by polymerase chain reaction (PCR) amplification of a 170-bp fragment using the primers: forward: 5'-GAAGAGTGATGTAT AGCCCCAG-3', reverse: 5'-TTTAATCCAGAGCTAATGAAAGCC-3'. The design of primers was carried out by a biological engineering company. The PCR products were cleaved by N1aW for restriction enzyme digestion. The digested products were analyzed on a $4 \%$ agarose gel, stained with ethidium bromide, and examined under UV transillumination. The nondigested 170-bp fragment corresponded to the L allele; a 126-bp fragment corresponded to the $\mathrm{M}$ allele; and 170- and 126-bp fragments corresponded to the LM heterozygous form (Figure 1).

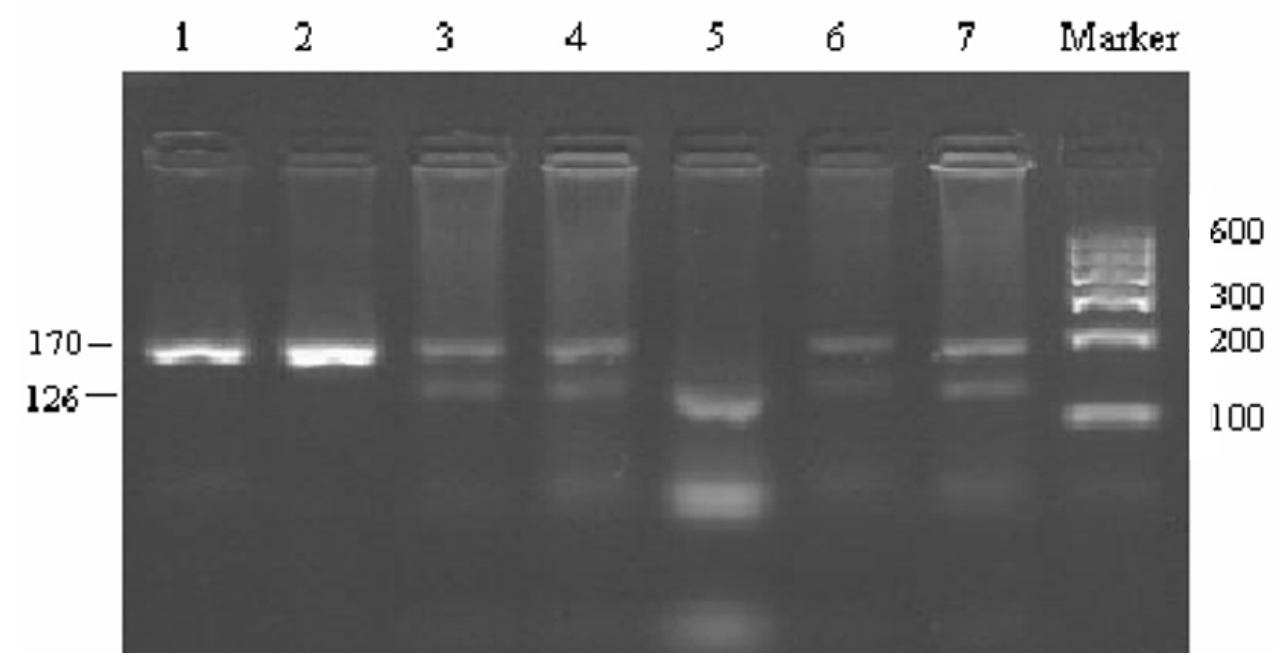

Figure 1. Electrophoresis of the PCR products of the PON1L55M. Lane Marker = marker-1; lanes 1 and $2=$ LL genotype; lanes 3, 4, 6, and 7= LM genotype; lane 5= MM genotype. 
Genotyping of the PON2C311S polymorphism was done by PCR amplification of a 226-bp fragment using the primers: forward 5'-AAGATTGGTAACTGCTAT-3', reverse 5'-GGCTACAGAACTTCCTTG-3'. The PCR products were cleaved by DdeI for restriction enzyme digestions. The digested products were analyzed on a $4 \%$ agarose gel, stained with ethidium bromide, and examined under UV transillumination. The undigested 226-bp fragment corresponded to the $\mathrm{C}$ allele; the 159-bp fragment corresponded to the $\mathrm{S}$ allele; and the 170- and 126-bp fragments corresponded to the CS heterozygous form (Figure 2).

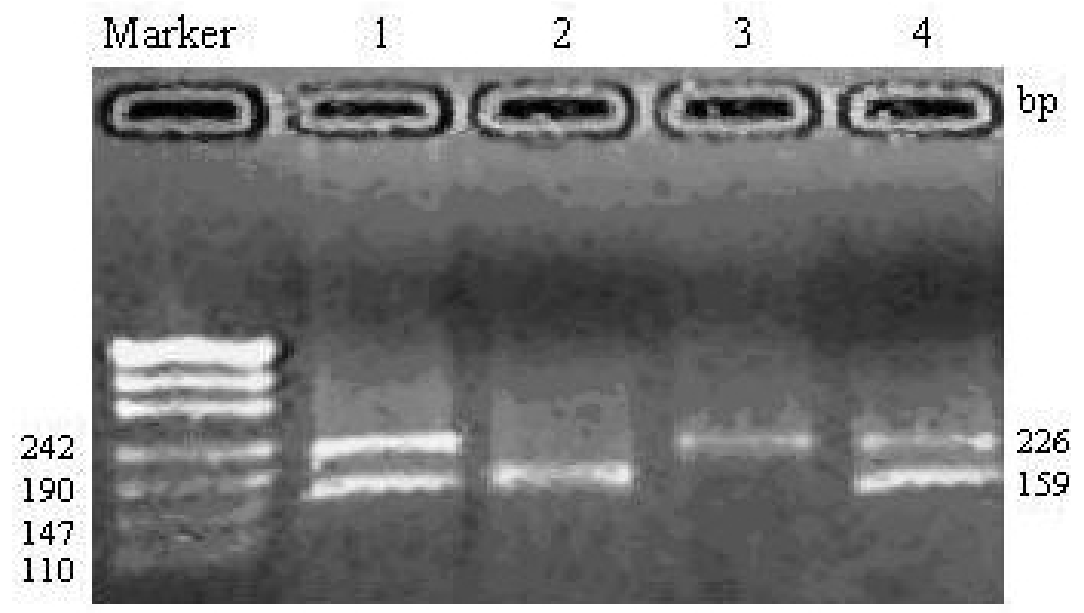

Figure 2. Electrophoresis of the PCR products of the PON2 S311C. Lane Marker = PUC-19; lanes 1, and $4=\mathrm{CS}$ genotype; lane 2 = SS genotype; lane $3=\mathrm{CC}$ genotype

\section{Statistical analysis}

The Statistical Package for Social Sciences (SPSS15.0) was used for data analysis. HW equilibrium was assessed by the $\chi^{2}$ test. Categorical variables among the paraoxonase genotypes were compared by the $\chi^{2}$ test. Normally distributed continuous variables were compared by the $t$ test or 1-way ANOVA. Logistic multivariate regression was used to adjust for possible confounding factors in the comparison of risk factors between paraoxonase genotypes. Allele frequencies were calculated by the gene counting method. A P $<0.05$ was considered to be statistically significant.

\section{RESULTS}

\section{Participant characteristics}

Table 1 shows the clinical characteristics of all subjects. In the Han people, the CAAD group had higher SBP, LDL-C and ApoB levels than those in the control group $(\mathrm{P}<0.05)$, but there were no differences in the rest (BMI, DBP, FPG, TC, TG, HDL-C, and ApoA1) between the two groups $(\mathrm{P}>0.05)$. In the Uighur people, the CAAD group had higher ApoB and ApoA1 levels than those in the control group $(\mathrm{P}<0.05)$, but there were no differences in the rest (BMI, SBP, DBP, FPG, TC, TG, HDL-C, and LDL-) between the two groups $(\mathrm{P}>0.05)$ (Table 1). 
Table 1. Comparison of clinical characteristics between CAAD group and control group.

\begin{tabular}{|c|c|c|c|c|c|c|}
\hline & \multicolumn{2}{|c|}{ Han people } & \multirow[t]{2}{*}{$\mathrm{P}$} & \multicolumn{2}{|c|}{ Uighur people } & \multirow[t]{2}{*}{$\mathrm{P}$} \\
\hline & $\mathrm{CAAD}(\mathrm{N}=230)$ & Control $(\mathrm{N}=123)$ & & $\operatorname{CAAD}(\mathrm{N}=141)$ & Control $(\mathrm{N}=99)$ & \\
\hline Gender (male, \%) & 56.52 & 50.41 & 0.22 & 62.41 & 59.60 & 0.68 \\
\hline Age (years) & $60.32 \pm 12.53$ & $59.41 \pm 12.31$ & 0.05 & $58.71 \pm 9.74$ & $57.23 \pm 10.1$ & 0.05 \\
\hline BMI $\left(\mathrm{kg} / \mathrm{m}^{2}\right)$ & $25.96 \pm 3.67$ & $25.22 \pm 4.26$ & 0.18 & $27.17 \pm 3.45$ & $26.81 \pm 6.40$ & 0.77 \\
\hline $\mathrm{SBP}(\mathrm{mmHg})$ & $144 \pm 20$ & $141 \pm 18$ & $0.04 *$ & $145 \pm 25$ & $148 \pm 28$ & 0.64 \\
\hline $\mathrm{DBP}(\mathrm{mmHg})$ & $90 \pm 14$ & $85 \pm 13$ & 0.05 & $92 \pm 22$ & $86 \pm 15$ & 0.12 \\
\hline FPG $(\mathrm{mM})$ & $5.52 \pm 1.77$ & $5.23 \pm 1.15$ & 0.09 & $5.71 \pm 3.16$ & $5.40 \pm 1.26$ & 0.16 \\
\hline $\mathrm{TC}(\mathrm{mM})$ & $4.56 \pm 1.25$ & $4.42 \pm 0.85$ & 0.28 & $4.36 \pm 0.48$ & $3.97 \pm 1.33$ & 0.06 \\
\hline $\mathrm{TG}(\mathrm{mM})$ & $2.23 \pm 1.38$ & $2.23 \pm 1.52$ & 0.98 & $2.81 \pm 1.46$ & $2.16 \pm 0.51$ & 0.06 \\
\hline HDL (mM) & $1.28 \pm 0.43$ & $1.25 \pm 0.63$ & 0.65 & $1.09 \pm 0.28$ & $1.20 \pm 0.26$ & 0.99 \\
\hline $\mathrm{LDL}(\mathrm{mM})$ & $2.84 \pm 0.90$ & $2.39 \pm 0.89$ & $0.02 *$ & $2.38 \pm 0.66$ & $2.04 \pm 0.67$ & 0.06 \\
\hline ApoA1 (g/L) & $1.24 \pm 0.18$ & $1.23 \pm 0.20$ & 0.50 & $1.18 \pm 0.21$ & $1.37 \pm 0.24$ & $0.00^{*}$ \\
\hline $\operatorname{ApoB}(g / L)$ & $0.92 \pm 0.23$ & $0.84 \pm 0.26$ & $0.02 *$ & $1.00 \pm 0.42$ & $0.83 \pm 0.22$ & $0.02 *$ \\
\hline
\end{tabular}

$* \mathrm{P}<0.05 . \mathrm{BMI}=$ body mass index $; \mathrm{SBP}=$ systolic blood pressure $; \mathrm{DBP}=$ diastolic blood pressure $; \mathrm{FPG}=$ fasting plasma glucose; $\mathrm{TC}=$ total cholesterol; $\mathrm{TG}=$ triglyceride; $\mathrm{HDL}=$ high density lipoprotein; $\mathrm{LDL}=$ low density lipoprotein; ApoA1 = apolipoprotein A1; ApoB = apolipoprotein B.

\section{Hardy-Weinberg (HW) equilibrium}

HW genetic balance is a kind of genetic traits or a genetic markers frequencies of occurrence in a large enough random group, it will balance throughout your generations without the join of new genes, mutation and the natural selection We applied the HW software to perform chi-square tests. Tables 2 and 3 show that the genotype distribution of the SNP in the coding sequence (L55M and C311S) was in agreement with frequencies expected under HW equilibrium, indicating genetic balance and representative of group.

Table 2. Assessment of Hardy-Weinberg equilibrium for PON1L55M polymorphisms.

\begin{tabular}{|c|c|c|c|c|c|c|c|}
\hline Ethnicity & Group & & LL & LM & MM & $\chi^{2}$ & $\mathrm{P}$ \\
\hline \multicolumn{8}{|l|}{ Han } \\
\hline & CAAD & Observed & 171 & 58 & 1 & 2.87 & 0.09 \\
\hline & & Expected & 174.1 & 52.0 & 3.9 & & \\
\hline & Control & Observed & 104 & 18 & 1 & 0.05 & 0.82 \\
\hline & & Expected & 104.1 & 18.1 & 0.79 & & \\
\hline \multicolumn{8}{|l|}{ Uighur } \\
\hline & CAAD & Observed & 110 & 30 & 1 & 0.47 & 0.50 \\
\hline & & Expected & 111.7 & 27.6 & 1.7 & & \\
\hline & Control & Observed & 74 & 24 & 1 & 0.39 & 0.53 \\
\hline & & Expected & 74.9 & 22.4 & 1.7 & & \\
\hline
\end{tabular}

Table 3. Assessment of Hardy-Weinberg equilibrium for PON2C311S polymorphisms.

\begin{tabular}{|c|c|c|c|c|c|c|c|}
\hline Ethnicity & Group & & SS & $\mathrm{CS}$ & $\mathrm{CC}$ & $\chi^{2}$ & $\mathrm{P}$ \\
\hline \multicolumn{8}{|l|}{ Han } \\
\hline & CAAD & Observed & 93 & 86 & 34 & 3.35 & 0.07 \\
\hline & & Expected & 87.2 & 98.2 & 27.6 & & \\
\hline & Control & Observed & 59 & 39 & 6 & 0.02 & 0.89 \\
\hline & & Expected & 58.5 & 39 & 6.5 & & \\
\hline \multicolumn{8}{|l|}{ Uighur } \\
\hline & CAAD & Observed & 59 & 57 & 25 & 2.83 & 0.09 \\
\hline & & Expected & 54.2 & 66.4 & 20.4 & & \\
\hline & control & Observed & 63 & 30 & 6 & 0.86 & 0.35 \\
\hline & & Expected & 61.8 & 32.8 & 4.4 & & \\
\hline
\end{tabular}




\section{PON1L55M and PON2C311S genotype and allele frequencies}

The Han and Uighur people showed the LL type gene mainly in the CAAD group and control group, the L allele frequency was significantly higher in the CAAD group than in the control group. Table 4 shows that in the Han people the frequency of the PON1 M allele was significantly higher in the CAAD group than control group $\left(\chi^{2}=4.038, \mathrm{P}=0.044\right)$. In the Uighur people, the difference in the frequencies of the PON1 genotypes and alleles was not statistically significant $(\mathrm{P}>0.05)$ (Table 4).

Table 4. Distribution of PON1L55M genotype and allele frequencies in CAAD and control.

\begin{tabular}{|c|c|c|c|c|c|c|c|}
\hline \multirow[t]{2}{*}{ Ethnicity } & \multirow[t]{2}{*}{ Group } & \multirow[t]{2}{*}{ Number } & \multicolumn{3}{|c|}{ Genotype frequency (\%) } & \multicolumn{2}{|c|}{ Allele frequency } \\
\hline & & & LL & LM & MM & $\mathrm{L}$ & $M$ \\
\hline \multirow[t]{2}{*}{$\overline{\operatorname{Han}}$} & CAAD & 230 & $171(74.3)$ & $58(25.2)$ & $1(0.4)$ & $0.87 *$ & $0.13^{*}$ \\
\hline & Control & 123 & $104(84.6)$ & $18(14.6)$ & $1(0.8)$ & 0.92 & 0.08 \\
\hline \multirow[t]{2}{*}{ Uighur } & CAAD & 141 & $110(78.0)$ & $30(21.3)$ & $1(0.7)$ & 0.89 & 0.11 \\
\hline & Control & 99 & $74(74.7)$ & $24(24.2)$ & $1(1.1)$ & 0.87 & 0.13 \\
\hline
\end{tabular}

*Compared with control group, $\mathrm{P}<0.05$.

The Han and Uighur people have the SS type gene mainly in the CAAD group and control group, the $\mathrm{S}$ allele frequency was significantly higher in the CAAD group than in the control group. Table 5 shows that in the Uighur people the frequencies of the PON2 CC/CS genotype and $\mathrm{C}$ allele were significantly higher in the CAAD group than control group $\left(\chi^{2}=\right.$ $\left.8.39, \mathrm{P}=0.02 ; \chi^{2}=8.64, \mathrm{P}=0.00\right)$. In the Uighur people, the frequencies of the PON2 CC/CS genotype and $\mathrm{C}$ allele were significantly higher in the CAAD group than control group $\left(\chi^{2}=\right.$ 13.2, $\left.\mathrm{P}=0.001, \chi^{2}=15.2, \mathrm{P}=0.00\right)$ (Table 5).

\begin{tabular}{|c|c|c|c|c|c|c|c|}
\hline \multirow[t]{2}{*}{ Ethnicity } & \multirow[t]{2}{*}{ Group } & \multirow[t]{2}{*}{ Number } & \multicolumn{3}{|c|}{ Genotype frequency (\%) } & \multicolumn{2}{|c|}{ Allele frequency } \\
\hline & & & SS & $\mathrm{CS}$ & $\mathrm{CC}$ & $\mathrm{S}$ & $\mathrm{C}$ \\
\hline \multirow[t]{2}{*}{ Han } & CAAD & 213 & 93 (43.6)* & $86(40.4)^{*}$ & $34(16.0) *$ & $0.64 *$ & $0.36^{*}$ \\
\hline & Control & 104 & $59(56.7)$ & $39(37.5)$ & $6(5.8)$ & 0.75 & 0.25 \\
\hline \multirow[t]{2}{*}{ Uighur } & CAAD & 141 & $59(41.8)^{*}$ & $57(40.4)^{*}$ & $25(17.7)^{*}$ & $0.62 *$ & $0.38 *$ \\
\hline & Control & 99 & $63(63.6)$ & $30(30.3)$ & $6(6.1)$ & 0.79 & 0.21 \\
\hline
\end{tabular}

*Compared with control group, $\mathrm{P}<0.05$.

\section{Logistic regression analysis}

Other risk factors of carotid artery atherosclerotic lesions (such as age, blood pressure, body mass index, FPG, TC, TG, and LDL, ApoB, ApoA1 and so on), make a single factor logistic regression analysis, and find meaningful risk factors for blood pressure, TC, TG and LDL ApoB, protection factor for ApoA1. Introduce these factors, PON1L55M (M allele) and PON2C311S (C alleles) to multiple factors logistic regression analysis ,judging independent risk factor for carotid atherosclerotic lesions in Han and Uighur Hypertension people of Xinjiang. Table 6 shows the relative contribution of the paraoxonase genotype to the presence of carotid artery atherosclerotic disease by multinomial logistic regression analysis. This analysis demonstrated the $\mathrm{M}$ allele and the $\mathrm{C}$ allele to be significantly and independently associated 
with CAAD in the Han people, while the $\mathrm{C}$ allele to be significantly and independently associated with CAAD in the Uighur people (Table 6).

Table 6. Multinomial logistic regression analysis of predictors of carotid artery atherosclerotic disease.
\begin{tabular}{llcccccc}
\hline Ethnicity & Variable & $\beta$ & SE & Wald & P & Exp (B) & $95 \%$ CI \\
\hline Han & LDL (mM) & 0.712 & 0.301 & 5.592 & 0.018 & 2.037 & $1.129-3.674$ \\
& SBP (mmHg) & 0.025 & 0.012 & 4.226 & 0.040 & 1.025 & $1.001-1.050$ \\
& PON1 M allele & 0.349 & 0.145 & 5.837 & 0.016 & 1.889 & $1.066-3.345$ \\
& PON2 C allele & 0.795 & 0.363 & 4.803 & 0.028 & 1.452 & $1.222-1.919$ \\
Uighur & ApoA1(g/L) & -7.929 & 3.486 & 5.175 & 0.023 & 0.000 & $0.000-0.334$ \\
& ApoB (g/L) & 0.108 & 0.019 & 30.97 & 0.000 & 1.314 & $1.170-1.443$ \\
& PON2 C allele & 0.953 & 0.365 & 6.767 & 0.019 & 1.292 & $1.054-1.715$ \\
\hline
\end{tabular}

$\mathrm{LDL}=$ low density lipoprotein; $\mathrm{SBP}=$ systolic blood pressure; $\mathrm{Apo} \mathrm{A} 1=$ apolipoprotein $\mathrm{A} 1 ; \mathrm{ApoB}=\operatorname{apolipoprotein} \mathrm{B}$.

Table 7 shows that the odds ratio (OR) estimated by the combined analysis of the PON1 55M allele and PON2 311C allele (OR $=1.428)$ was not higher than that estimated separately from the PON1 55M allele $(\mathrm{OR}=1.889)$, PON2 $311 \mathrm{C}$ allele $(\mathrm{OR}=1.692)$ alone. PON1L55M and PON2C311S may not have a synergistic effect on CAAD (Table 7).

Table 7. Analysis of the combined genotypes of PON1L55M and PON2C311S.
\begin{tabular}{lccc}
\hline Gene & CAAD group (N, $\%)$ & Control group (N, $\%)$ & OR (95\%CI) \\
\hline PON1L55M & $59(25.65 \%)$ & $19(15.45 \%)$ & $1.889(1.066-3.345)$ \\
M allele & $171(74.35 \%)$ & $104(84.55 \%)$ & \\
No M allele & $120(56.34 \%)$ & $45(43.27 \%)$ & $1.692(1.054-2.715)$ \\
PON2C311S & $93(43.66 \%)$ & $59(56.73 \%)$ & $1.428(1.783-2.601)$ \\
C allele & $49(4.23 \%)$ & $18(3.85 \%)$ & \\
No C allele & $164(95.77 \%)$ & $86(96.15 \%)$ & \\
PON1L55M+PON2C311S & & \\
M+C allele & & \\
No M+C allele &
\end{tabular}

\section{DISCUSSION}

Two genetic variants in the PON1 gene locus (L55M and T-107C) are determinants for the bioavailability of PON1 in blood (Leviev and James, 2000). A Q192R SNP is a genetic determinant of PON1 hydrolytic activity towards paraoxon (Mackness et al., 1998). Our study showed that the PON155M allele was a significant risk factor for CAAD in Xinjiang Han with hypertension. This outcome is in agreement with several other studies. Rontu (Rontu et al., 2003, 2004) reported that the $\mathrm{M}$ allele carriers had larger atherosclerotic lesions compared to LL homozygous individuals. However, Malin et al. (2001b) and Schmidt et al. (1998) detected a significant association between the LL genotype and degrees of severity of CAAD, showing that the L allele was an independent risk factor for CAAD. On the other hand, Hong et al. (2001) concluded that there was no significant association between PON1L55M polymorphism and CAAD. Our study showed that there was no significant association between PON1L55M polymorphism and CAAD in the Xinjiang Uighur people with hypertension. There are several reasons that may account for the differences between these studies. Selection bias, population difference in ethnicity, and difference in the criteria used for defining phenotype between studies cannot be ruled out.

Like PON1, PON2 has several polymorphisms that are associated with a number of pathophysiologic conditions. Population studies have yielded a pair of amino acid substitu- 
tions with an alanine or glycine at codon $148(\mathrm{~A} / \mathrm{G} 148)$ and either cysteine or serine at codon $311(\mathrm{C} / \mathrm{S} 311)$. The $\mathrm{A} / \mathrm{G} 148$ polymorphism has been associated with variations in total and LDL-C levels, FPG levels, and birth weight (Hegele et al., 1997, 1998). The polymorphism at position 311 has been associated with coronary artery disease, ischemic stroke in patients with type 2 diabetes mellitus, late-onset Alzheimer's disease, and reduced bone mass in postmenopausal women (Kao et al., 2002; Chen et al., 2003; Yamada et al., 2003; Martinelli et al., 2004; Shi et al., 2004). Our study showed that the PON2 C allele is a significant risk factor for CAAD in the Xinjiang Han and Uighur people with hypertension. There are few reports about the relationship between PON2 C311S polymorphisms and CAAD, but there are many reports about the relationship between PON2 C311S polymorphisms and ischemic stroke and coronary artery disease. Wang et al. (2004) reported that the PON2 311C allele frequency was clearly increased in type 2 diabetes patients with ischemic stroke. Yang et al. (2006) believe that the PON2 311C allele is an independent risk factor for ischemic stroke. Martinelli et al. (2004) reported that the PON2 311C allele clearly increases the risk of myocardial infarction in Italy. In a recent study in white women (Chen et al., 2003), the PON2 CC genotype showed a higher frequency with coronary artery disease. Our study confirmed that the PON2 C allele is a significant risk factor for CAAD in the Xinjiang Han and Uighur people with hypertension. We speculate that the $\mathrm{C}$ allele could lead to changes in the structure and function of PON2 enzymes, which would influence lipid metabolism and cause a reduction in HDL-C antioxidant capacity and promote biochemical changes in the development of atherosclerosis. However, opposite conclusions have been reported. Leus et al. (2001) reported that the PON2 CC genotype may be a protective factor against cardiovascular disease. Imai et al. (2001) showed that there was no significant association between PON2 C311S polymorphism and coronary artery disease or ischemic stroke in Japan. These reports are not consistent, where sample size, ethnic differences, and environmental factors may account for the differences. We aim to perform a further study in the future to address these questions.

Our study showed that the OR estimated by the combined analysis of the PON1 55M allele and PON2 311C allele was not higher than that estimated separately for the PON1 55M allele and PON2 311C allele alone. The results suggested that PON1L55M and PON2C311S may not have a synergistic effect on CAAD. The problem that the gene locus plays an independent role, or that there is an interaction between the polymorphisms, or that the development of CAAD is more complex, still needs further study.

The present study about PON has rarely been repeated and confirmed in different populations. Our study confirmed that PON1 55M alleles and PON2 311C alleles increase the risk of CAAD in the Sinjiang Han population and that PON2 311C alleles increase the risk of CAAD in the Xinjiang Uighur population. Although the genetic pattern of the multiple gene disease is not confirmed at present, we will find a new approach to the prevention and treatment of CAAD in patients with hypertension in our study of genetic susceptibility genes with the progress of the human genome project.

\section{ACKNOWLEDGMENTS}

Research supported by the National Natural Science Fund Projects of China-Genetic susceptibility gene in vascular aging with Uygur, Kazak healthy population and natural longevity in the Xinjiang (\#30860296). 


\section{REFERENCES}

Aviram M, Rosenblat M, Bisgaier CL, Newton RS, et al. (1998). Paraoxonase inhibits high-density lipoprotein oxidation and preserves its functions. A possible peroxidative role for paraoxonase. J. Clin. Invest. 101: 1581-1590.

Chen Q, Reis SE, Kammerer CM, McNamara DM, et al. (2003). Association between the severity of angiographic coronary artery disease and paraoxonase gene polymorphisms in the National Heart, Lung, and Blood Institutesponsored Women's Ischemia Syndrome Evaluation (WISE) study. Am. J. Hum. Genet. 72: 13-22.

Durrington PN, Mackness B and Mackness MI (2001). Paraoxonase and atherosclerosis. Arterioscler. Thromb. Vasc. Biol. 21: 473-480.

Harangi M, Seres I, Magyar MT, Csipo I, et al. (2008). Association between human paraoxonase 1 activity and intimamedia thickness in subjects under 55 years of age with carotid artery disease. Cerebrovasc. Dis. 25: 122-128.

Hegele RA, Connelly PW, Scherer SW, Hanley AJ, et al. (1997). Paraoxonase-2 gene (PON2) G148 variant associated with elevated fasting plasma glucose in noninsulin-dependent diabetes mellitus. J. Clin. Endocrinol. Metab. 82: 3373-3377.

Hegele RA, Harris SB, Connelly PW, Hanley AJ, et al. (1998). Genetic variation in paraoxonase-2 is associated with variation in plasma lipoproteins in Canadian Oji-Cree. Clin. Genet. 54: 394-399.

Hong SH, Song J, Min WK and Kim JQ (2001). Genetic variations of the paraoxonase gene in patients with coronary artery disease. Clin. Biochem. 34: 475-481.

Imai Y, Morita H, Kurihara H, Sugiyama T, et al. (2000). Evidence for association between paraoxonase gene polymorphisms and atherosclerotic diseases. Atherosclerosis 149: 435-442.

Jander S, Sitzer M, Wendt A, Schroeter M, et al. (2001). Expression of tissue factor in high-grade carotid artery stenosis: association with plaque destabilization. Stroke 32: 850-854.

Jin YZ and Wang BN (2010). Clinical analysis on correlation risk factors of carotid arteries scleratheroma. Anhui Med. J. 31: 556-559.

Kao Y, Donaghue KC, Chan A, Bennetts BH, et al. (2002). Paraoxonase gene cluster is a genetic marker for early microvascular complications in type 1 diabetes. Diabet. Med. 19: 212-215.

Leus FR, Zwart M, Kastelein JJ and Voorbij HA (2001). PON2 gene variants are associated with clinical manifestations of cardiovascular disease in familial hypercholesterolemia patients. Atherosclerosis 154: 641-649.

Leviev I and James RW (2000). Promoter polymorphisms of human paraoxonase PON1 gene and serum paraoxonase activities and concentrations. Arterioscler. Thromb. Vasc. Biol. 20: 516-521.

Mackness B, Davies GK, Turkie W, Lee E, et al. (2001). Paraoxonase status in coronary heart disease: are activity and concentration more important than genotype? Arterioscler. Thromb. Vasc. Biol. 21: 1451-1457.

Mackness MI, Arrol S, Abbott C and Durrington PN (1993). Protection of low-density lipoprotein against oxidative modification by high-density lipoprotein associated paraoxonase. Atherosclerosis 104: 129-135.

Mackness MI, Mackness B, Durrington PN, Fogelman AM, et al. (1998). Paraoxonase and coronary heart disease. Curr. Opin. Lipidol. 9: 319-324.

Malin R, Jarvinen O, Sisto T, Koivula T, et al. (2001a). Paraoxonase producing PON1 gene M/L55 polymorphism is related to autopsy-verified artery-wall atherosclerosis. Atherosclerosis 157: 301-307.

Malin R, Loimaala A, Nenonen A, Mercuri M, et al. (2001b). Relationship between high-density lipoprotein paraoxonase gene M/L55 polymorphism and carotid atherosclerosis differs in smoking and nonsmoking men. Metabolism 50: 1095-1101.

Martinelli N, Girelli D, Olivieri O, Stranieri C, et al. (2004). Interaction between smoking and PON2 Ser311Cys polymorphism as a determinant of the risk of myocardial infarction. Eur. J. Clin. Invest. 34: 14-20.

Mathiesen EB, Bonaa KH and Joakimsen O (2001). Echolucent plaques are associated with high risk of ischemic cerebrovascular events in carotid stenosis: the tromso study. Circulation 103: 2171-2175.

Mochizuki H, Scherer SW, Xi T, Nickle DC, et al. (1998). Human PON2 gene at 7q21.3: cloning, multiple mRNA forms, and missense polymorphisms in the coding sequence. Gene 213: 149-157.

Nagai Y, Kitagawa K, Sakaguchi M, Shimizu Y, et al. (2001). Significance of earlier carotid atherosclerosis for stroke subtypes. Stroke 32: 1780-1785.

Ng CJ, Wadleigh DJ, Gangopadhyay A, Hama S, et al. (2001). Paraoxonase-2 is a ubiquitously expressed protein with antioxidant properties and is capable of preventing cell-mediated oxidative modification of low density lipoprotein. J. Biol. Chem. 276: 44444-44449.

$\mathrm{Ng}$ CJ, Shih DM, Hama SY, Villa N, et al. (2005). The paraoxonase gene family and atherosclerosis. Free Radic. Biol. Med. 38: 153-163.

Primo-Parmo SL, Sorenson RC, Teiber J and La Du BN (1996). The human serum paraoxonase/arylesterase gene (PON1) is one member of a multigene family. Genomics 33: 498-507.

Genetics and Molecular Research 12 (4): 5174-5185 (2013)

CFUNPEC-RP www.funpecrp.com.br 
Roest M, Rodenburg J, Wiegman A, Kastelein JJ, et al. (2006). Paraoxonase genotype and carotid intima-media thickness in children with familial hypercholesterolemia. Eur. J. Cardiovasc. Prev. Rehabil. 13: 464-466.

Rontu R, Karhunen PJ, Ilveskoski E, Mikkelsson J, et al. (2003). Smoking-dependent association between paraoxonase 1 M/L55 genotype and coronary atherosclerosis in males: an autopsy study. Atherosclerosis 171: 31-37.

Rontu R, Lehtimaki T, Ilveskoski E, Mikkelsson J, et al. (2004). Association of paraoxonase-1 M55L genotype and alcohol consumption with coronary atherosclerosis: the Helsinki Sudden Death Study. Pharmacogenetics 14: 479-485.

Sanghera DK, Aston CE, Saha N and Kamboh MI (1998). DNA polymorphisms in two paraoxonase genes (PON1 and PON2) are associated with the risk of coronary heart disease. Am. J. Hum. Genet. 62: 36-44.

Schmidt H, Schmidt R, Niederkorn K, Gradert A, et al. (1998). Paraoxonase PON1 polymorphism leu-Met54 is associated with carotid atherosclerosis: results of the Austrian Stroke Prevention Study. Stroke 29: 2043-2048.

Shi LH, Woodward DJ, Luo F, Anstrom K, et al. (2004). High-frequency stimulation of the subthalamic nucleus reverses limb-use asymmetry in rats with unilateral 6-hydroxydopamine lesions. Brain Res. 1013: 98-106.

Wang XY, Xue YM, Zhang NL, Ji Z, et al. (2004). Paraoxonase 2 gene C311S polymorphism observed of Han nationality in Guangdong region. Guangdong Med. J. 25: 24-25.

Watson AD, Berliner JA, Hama SY, La Du BN, et al. (1995). Protective effect of high density lipoprotein associated paraoxonase. Inhibition of the biological activity of minimally oxidized low density lipoprotein. J. Clin. Invest. 96: 2882-2891.

Yamada Y, Ando F, Niino N, Miki T, et al. (2003). Association of polymorphisms of paraoxonase 1 and 2 genes, alone or in combination, with bone mineral density in community-dwelling Japanese. J. Hum. Genet. 48: 469-475.

Yang HP, Zhao WJ, Shen YF and et al (2006). Association of PON2 311 and $\beta$-fibrinogen -455 gene polymorphism with atherothrombotic cerebral infarction. Clin. Med. Chin. 22: 217-220.

Yen Y, Lim DW, Chung V, Morgan RJ, et al. (2008). Phase II study of oxaliplatin in patients with unresectable, metastatic, or recurrent hepatocellular cancer: a California Cancer Consortium Trial. Am. J. Clin. Oncol. 31: 317-322.

Zhao H and Ding SJ (2005). Genetic Research in Carotid Atherosclerosi. Cerebrovasc. Dis. Foreign Med. Sci. 13: 232235.

Zou YQ and Ge XH (1999). Experienced Handbook of Ultrasonic Doppler for Cervica Artery. Xueyuan Chubanshe, Beijing. 